\title{
Association Between Alcohol Consumption and Nocturnal Leg Cramps
}

\author{
Elizabeth W. McIntosh, MD, Grant Family Medicine \\ Michael E. Jobansen, MD, MS Associate Editor
}

Ann Fam Med 2018;16(4):iii. https://doi.org/10.1370/afm.2142.

$\mathrm{T}$ The Annals of Family Medicine encourages readers to develop a learning community to improve health care and health through enhanced primary care. Participate by conducting a RADICAL journal club. RADICAL stands for Read, Ask, Discuss, Inquire, Collaborate, Act, and Learn. We encourage diverse participants to think critically about important issues affecting primary care and act on those discussions. ${ }^{1}$

\section{HOW IT WORKS}

In each issue, the Annals selects an article and provides discussion tips and questions. Take a RADICAL approach to these materials and post a summary of your conversation in our online discussion. (Open the article and click on "TRACK Discussion/ Submit a comment.") Discussion questions and information are online at: http://www.annfammed.org/site/AJC/.

\section{CURRENT SELECTION}

\section{Article for Discussion}

Delacour C, Chambe J, Lefebrvre F, et al. Association between alcohol consumption and nocturnal leg cramps in patients over 60 years old: a case-control study. Ann Fam Med. 2018;16(4):296-301.

\section{Discussion Tips}

Case-control studies can be useful to explore associations when diseases are rare or not well understood. ${ }^{2}$ Nocturnal leg cramps are a common but relatively self-limited condition of unclear pathophysiology, although associations with various medications (such as diuretics and quinine) have been proposed. This case-control study explores an interesting and novel association between nocturnal leg cramps and alcohol consumption.

\section{Discussion Questions}

- What question is asked by this study and why does it matter to a family physician?

- What is a case-control study? ${ }^{2}$ How is this different from a cohort study?
- What are the strengths and weaknesses of a casecontrol study design to answer a study question?

- How did the researchers find cases and match to control subjects? How did the case and control groups compare in terms of demographics and medical history?

- What are the main study findings? How were these calculated? What was the credibility interval around the point estimate?

- To what degree might the findings be affected by:

- How patients were selected, excluded, or lost to follow-up?

- The size of the study? How many matches were included of the 4 different combinations (Supplemental Appendix 5)?

- How the main variable of alcohol consumption was measured and categorized?

- Confounding (false attribution of causality because 2 variables discovered to be associated actually are associated with a 3rd factor)?

- Chance?

- What is a dose-effect relationship? Did they find a dose-effect relationship with alcohol? Does this strengthen or weaken the findings of the study?

- How comparable is the study sample to patients in your practice with nocturnal leg cramps?

- Is this study likely to change your clinical practice? In what way?

-What are the next steps to further investigate these findings?

\section{References}

1. Stange KC, Miller WL, McLellan LA, et al. Annals Journal Club: It's time to get RADICAL. Ann Fam Med. 2006;4(3):196-197. http:// annfammed.org/cgi/content/full/4/3/196.

2. Coggon D, Rose G, Barker DJP. Case-control and cross-sectional studies. In: Epidemiology for the Uninitiated. 4th ed. London, UK: The BMJ. https://www.bmj.com/about-bmj/resources-readers/publications/epidemiology-uninitiated/8-case-control-and-cross-sectional. Accessed Apr 12, 2018. 